\title{
Research on the Professional Development Attitude of Minority English Teachers*
}

\author{
Hui Shi \\ Institute of International Education, Jishou University, Hunan, China
}

\begin{abstract}
English teachers of different ages in middle schools are involved as quantitative research participants in this study. SPSS is applied to analyze the status quo and differences of their professional development attitude among different ages. The results show that they have the strong positive attitude toward their professional development, but teachers of different ages have significant differences in the dimensions of Professional Teaching Knowledge, Flexible Task Goals Consciousness as well as Rigid Task Target Consciousness.
\end{abstract}

Index Terms - minority English teachers, teachers' professional development attitude, differences in different age groups

\section{INTRODUCTION}

The professional development of FLT (foreign language teachers) has received increasing attention in the field of foreign language education in recent years. In the 1990s, the research on FLT education mainly focused on the teacher knowledge, teaching behavior and teacher learning, for instance, what was teacher knowledge, how to teach, and how to learn to teach. In terms of teacher's knowledge, it mainly analyzed the characteristics, construction and practice of teacher's knowledge from theory and practice (such as Richards, 1998; Wallace, 1991; Freeman \& Richards, 1993; Johnson, 1996; Freeman \& Johnson, 1998; Freeman, 1989); in terms of teaching behavior, it mainly focused on teacher's teaching behavior, decision-making and reflection (such as Lockhart \& Richards, 1994; zeichner \& liston, 1996; Woods, 1996; Borg, 1998; Ellis, 1997); in terms of teacher's learning, it mainly focused on the nature, approach, content and orientation of foreign language teacher's learning (such as Richards \& Nunan, 1990; Freeman \& Richards, 1996).

At the beginning of the 21st Century, the research on FLT was appeared "sociocultural turn" by the influence of postmodern trend of thought. Researchers studied FLT from the perspective of post structuralism, sociocultural theory, ecology and other emerging theories. They emphasized that the professional development of FLT couldn't be separated from the social and cultural environment. Therefore, as the participants, teachers needed in consultation with their social and cultural environment, paid more attention to their "inner self" in practice (such as Zembylas, 2003, 2005; Reeves, 2009; Velez-Rendon, 2010; Lee, 2013; Edwards \& Burns, 2016; Aneja, 2016; Yuan, 2016; Ellis, 2016; Barkhuizen, 2016; Kasun \& Saavedra, 2016). The trend of cultural turn in the field of FLT is the demand of the professional development of minority FLT, and has provided a new perspective and theoretical thinking for the study of the minority FLT's professional development as well.

Minority English teachers in middle schools are immersing in various cultural fields, such as the native culture, the mainstream culture as well as the foreign culture and so on, they may be puzzled by the differences in such multicultural situations. In addition, the unique professional emotions, the professional knowledge and the professional skills are taking shape in their educational practice because of the coexistence of different cultures, for instance, the sense of mission and responsibility of ethnic minorities can be constructed in teaching practice, and the multilingual teaching skills can be built due to their master multiple languages. Therefore, the research on minority FLT's professional development can better understand their inner psychological mechanism, improve the basic foreign language education in minority areas, stimulate their cultural consciousness, self-confidence as well as national identity, and improve their professional development.

\section{RESEARCH DESIGN}

\section{A. The Research Objects and Problems}

A total of 180 minority English teachers of different ages who come from Hunan and Guizhou in middle schools are involved as quantitative research participants in this study. The research questions of this study are: (1) What is the status quo of minority English teacher's professional development attitude in middle schools? (2) Are there any differences among different age groups?

\footnotetext{
* This research is one of the results of the 2019 Project of the $13^{\text {th }}$ Five-Year Plan of Education Science in Hunan Province, which is "Research on the Perplexity and Resolution of Professional Development of English Teachers in Minority Middle Schools" (No. Xjk19qmz001). 


\section{B. The Research Tools and Processes}

A Comprehensive Questionnaire on the Professional Development Attitude of Middle School English Teachers (Revised) (Xun, 2012) is used in this study as quantitative research tool. The revised version is consisted by 32 items in total, and including three sub questionnaires. According to the empirical test, the coefficient of internal consistency of $A$ Comprehensive Questionnaire on the Professional Development Attitude of Middle School English Teachers (Revised) is $\alpha=0.865$, among which the first sub questionnaire Instrumental Professional Development Sub Questionnaire's coefficient of internal consistency is $\alpha=0.786$, the second sub questionnaire Subjective Professional Development Sub Questionnaire's coefficient of internal consistency is $\alpha 0.806$, and the coefficient of internal consistency of the third sub questionnaire Cultural Influence Sub Questionnaire has not been analyzed by the reviser. In this study, the reliable data is obtained by the distribution, collection as well as statistics of questionnaires, and SPSS is applied to analyze the data to get the status quo of minority English teacher's professional development attitude and the differences of different age groups.

\section{General Descriptive Statistics of Professional Development Attitude}

A Comprehensive Questionnaire on the Professional Development Attitude of Middle School English Teachers (Revised) is composed by three sub questionnaires and nine dimensions, of which the sub questionnaire Instrumental Professional Development Sub Questionnaire containing five dimensions: The Satisfaction of Professional Teaching Ability, Role Awareness, Professional Teaching Knowledge, Flexible Target Task Characteristics, Rigid Target Task characteristics. The sub questionnaire Subjective Professional Development Sub Questionnaire is composed by three dimensions: Systematic Thinking and Self-Transcendence, Improving Mental Models, Shared Vision and Team Learning. The sub questionnaire Cultural Influence Sub Questionnaire only consisted by one dimension is Cultural Influence.

It can be seen from the table 3-1 that the mean value of sub questionnaire Instrumental Professional Development is 4.206, the mean value of sub questionnaire Subjective Professional Development is 4.116, and the mean value of sub questionnaire Cultural Influence is 3.514. It shows that the overall sample of the study has a high professional development attitude, that is to say, minority English teachers in middle schools hold a positive attitude to their professional development.

TABLE 3-1

THE DESCRIPTION STATISTICS OF PROFESSIONAL DEVELOPMENT ATTITUDE(N=180)

\begin{tabular}{lllll}
\hline & Min & Max & Mean & Std. Deviation \\
\hline Instrumental Professional Development & 1.00 & 5.00 & 4.206 & 0.692 \\
Subjective Professional Development & 1.00 & 5.00 & 4.116 & 0.732 \\
Cultural Influence & 1.00 & 5.00 & 3.514 & 0.868 \\
Professional Development Attitude & 1.30 & 5.00 & 3.945 & 0.764 \\
\hline
\end{tabular}

What we can see from the Table 3-2 is the average value and standard deviation of each dimension in the professional development attitude of minority English teachers in middle schools. Among the eight dimensions, the lowest average score is 3.514, which indicates that the culture of English-speaking country has a certain impact on minority English teachers' thinking, but it is not very obvious (TableT3-3). The results are consistent with the findings of Xun (2012), but her research objects are English teachers in high school.

In addition, the mean value of other dimensions are higher than 4. Among them, the highest is 4.266, which is the dimension of Rigid Task Goal Awareness. The order of the average value of each factor is: Rigid Task Goal Consciousness (4.266) > Professional Role Consciousness (4.255) > Professional Teaching Ability Satisfaction (4.248) > Improving Mental Model (4.227) > Flexible Task Goal Consciousness (4.190) > Systematic Thinking and Self-transcendence (4.091) > Professional Teaching Knowledge (4.072) > Common Vision and Team Learning (4.029) > Cultural Influence (3.514).

TABLE 3-2

DESCRIPTIVE STATISTICS Of THE MEAN AND STANDARD DEVIATION OF VARIOUS Dimensions OF The Professional DeVElopment ATtiTude(N=180)

\begin{tabular}{lcccc}
\hline \multicolumn{1}{c}{ Dimensions } & Min & Max & Mean & Std. Deviation \\
\hline Professional Teaching Ability Satisfaction & 1.00 & 5.00 & 4.248 & 0.698 \\
Professional Role Consciousness & 1.00 & 5.00 & 4.255 & 0.677 \\
Professional Teaching Knowledge & 2.00 & 5.00 & 4.072 & 0.720 \\
Flexible Task Goal Consciousness & 2.00 & 5.00 & 4.190 & 0.688 \\
Rigid Task Goal Consciousness & 1.00 & 5.00 & 4.266 & 0.680 \\
Systematic Thinking and Self-transcendence 1.00 & 1.00 & 5.00 & 4.091 & 0.750 \\
Improving Mental Model & 1.00 & 5.00 & 4.227 & 0.630 \\
Common Vision and Team Learning & 1.00 & 5.00 & 4.029 & 0.816 \\
Cultural Influence & & 5.00 & 3.514 & 0.868 \\
\hline
\end{tabular}


TABLE 3-3

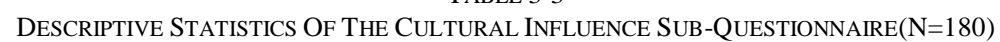

\begin{tabular}{ccccc}
\hline & Min & Max & Mean & Std. Deviation \\
\hline Z30 & 1.00 & 5.00 & 3.183 & 0.899 \\
Z31 & 1.00 & 5.00 & 3.422 & 0.832 \\
Z32 & 1.00 & 5.00 & 3.938 & 0.872 \\
Cultural Influence & 1.30 & 5.00 & 3.514 & 0.868 \\
\hline
\end{tabular}

\section{DifFEREnCE Statistics by Age Classification}

In order to further explore the deeply significance which behind the data, the study uses the statistical method of one-way ANOVA to further analyze the differences of English teacher's professional development attitude from the age classification. Small probability proof method is used in this study, that is, taking the significance level as 0.05 significant difference, when significance level is 0.01 , which means the difference is very significant (the difference is significant (i.e. when $t \geq t(D F) ~ 0.05, P \leq 0.05$, the difference is significant; when $t \geq t$ (DF) $0.01, P \leq 0.01$, the difference is very significant); on the contrary, when the significance level is higher than 0.05 , which means the difference is not significant (Zhang \& Kuang, 2013: 3).

Table 3-4 shows the analysis results of descriptive statistics and one-way ANOVA of minority English teacher's professional development attitude in different age groups. Based on the results in Table 3-4, it can be claimed that among the 9 dimensions, there are significant differences in Professional Teaching Knowledge $(\mathrm{P} \leq 0.01)$, Flexible Task Goal Consciousness $(\mathrm{P} \leq 0.05)$ and Rigid Task Goal Consciousness $(\mathrm{P} \leq 0.01)$, while no significant differences in other dimensions.

The dimension of Professional Teaching Knowledge in Table 3-4 is used to measure teacher's knowledge mastery level in foreign language teaching, for instance, understanding foreign language teaching method, comprehending the new English Curriculum Standard and their role. In this dimension, the highest mean value is 4.333, which appears in the group who over 50 years old. The next are those who between 41 and 50 years old, and the lowest mean value is 3.984 , which in the group who under 30 years old. Compared with teachers at other ages, those who over 50 years old have the highest level as well as ability to master the related knowledge in the process of foreign language teaching, and they can understand the new English Curriculum Standard very well.

The dimension of Flexible Target Task Consciousness is to measure the ability that teachers adopt flexible strategies and methods in the process of completing the given teaching tasks. In this dimension, the highest mean value is 4.410, which in the group who over 50 years old. Compared with other age groups, those who over 50 years old have the strongest ability to adopt flexible strategies and methods in the process of completing the given teaching tasks.

Rigid Target Task Consciousness refers to the situation that teachers can't adopt flexible strategies and methods when completing the given teaching tasks. In this dimension, the highest mean value is 4.50 , which in the group who aged 30 and below. The average value of teachers aged 31-41 and 41-50 are the middle level; and the lowest mean value is 4.012, which in the group who aged 50 and above. Compared with other ages, those who aged 30 and below have the lowest ability to adopt flexible strategies and methods in the process of completing the given teaching tasks. Furthermore, their ability to adopt flexible strategies and methods will increases gradually as the growth of age groups.

Ye \& Bai (2001) divided the process of teacher's professional development into five stages: the non-attention stage, the virtual attention stage, the survival attention stage, the task attention stage as well as the self-update attention stage. Generally speaking, the special-grade teacher, senior teachers or teachers with more than 20 years of teaching experience are called expert teachers; those who have just worked for 1-3 years or with less than 5 years of teaching experience are novice teachers; and those who are in the middle stage are skilled teachers.

Based on the analysis of the qualitative interviews in the later period, it is learned that many expert teachers with the teaching age of more than 20 years are mainly in the stage of "self-update attention". Teachers at this stage are relatively free in teaching attitudes, behaviors as well as ideas, they don't follow the teaching plan or teaching materials completely while teaching, and the personal practical knowledge with their own characteristics has been constructed by reflection on the professional experience. They are able to fully consider the environmental variables to change the teaching plans and strategies, which make a strong transformation ability between practical knowledge and theoretical knowledge has been built.

Those who aged 31-50 are proficient teachers, most of them are mainly in the stage of "task attention", which is a stable and sustainable period of teacher's professional structures. Teachers take shape development plans and professional ideals with their own characteristics in this stage. They are familiar with all aspects and teaching strategies of teaching, and can carry out various teaching designs flexibly as well as creatively in teaching process. However, some teachers may suffer from "plateau phenomenon" in this stage, which refers to lack of motivation in their professional development.

Those who under the age of 30 are mainly the novice teachers with teaching age less than 6 years, most of them are in the stage of "survival attention". In teaching practice, they mainly focus on the relationship with students, and the management of student's discipline in classroom. They hope to be recognized by students, colleagues and superiors. However, some of them lack of internal thinking or deep thinking in teaching practice, and a tendency of foreign 
language teaching is often used in their teaching.

TABLE 3-4

ANALYSIS OF VARIANCE IN ALL DIMENSIONS OF PROFESSIONAL DEVELOPMENT BY AGE GROUPS

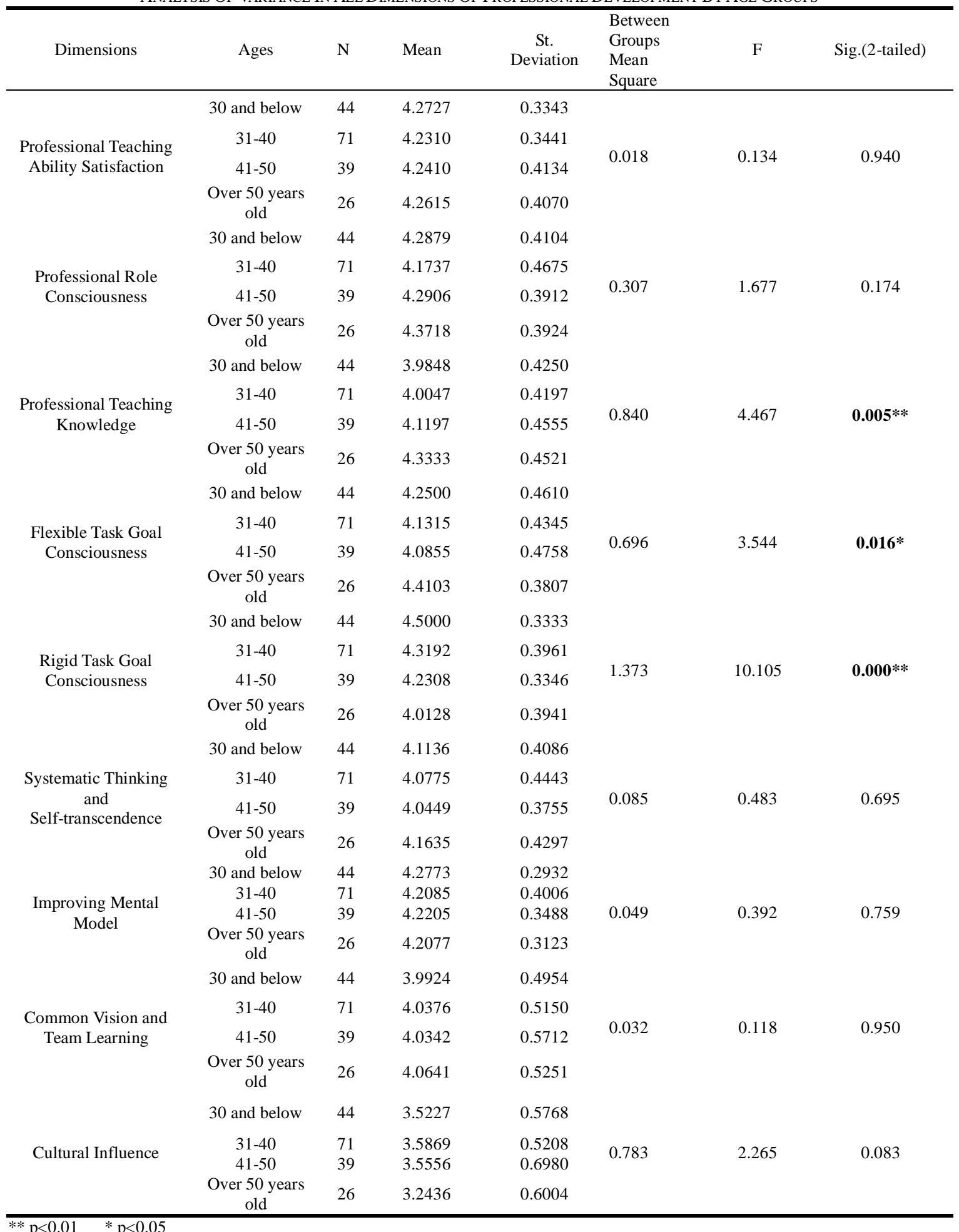

In order to further understand the reasons for the differences in professional development attitude of minority English teachers in different age groups, the study analyzes three dimensions of Professional Teaching Knowledge $(\mathrm{P} \leq 0.01)$, Flexible Task Goal Awareness $(\mathrm{P} \leq 0.05)$ and Rigid Task Goal Awareness $(\mathrm{P} \leq 0.01)$ with one-way ANOVA.

At the dimension of Professional Teaching Knowledge in Table 3-5, item 5 "In teaching, I prefer to summarize the personal teaching experience" has a very significant difference because of the $\mathrm{P}=0.000(<0.01)$, which is the main reason why the difference exists. In item 5, we can see that the lowest mean value 3.477 is appeared in the group of teachers who under the age of 30, the middle level 3.676 is showed in the age of 31-40, and the highest is the age of 
over 50 with an average of 4.692. Compared with teachers of other ages, the age over 50 years are more inclined to summarize the personal teaching experience, they can integrate knowledge of curriculum, teaching strategies as well as personal experience during the process of teaching, while teachers who under 30 years old are relatively weaker than other groups in the ability of summarizing personal teaching experience.

At the dimension of Flexible Task Goal Awareness in Table 3-6, item 18 "I have the ability to choose and use teaching methods correctly", in which $\mathrm{P}=0.000(<0.01)$ is the main reason for the difference. In item 18 , the highest mean value 4.69 is appeared in teachers who over 50 years old, compared with other age groups, teachers over 50 years old can use and select teaching methods flexibly, and constructs their ability to select and use teaching methods correctly in teaching practice.

At the dimension of Objective Consciousness of Rigid Task in Table 3-7, item 12 "my teaching plan is very detailed, and I complete the teaching task according to teaching plan in class completely", in which $\mathrm{P}=0.000(<0.01)$ is the main reason for the difference. We can see that the lowest mean value 2.923 is appeared in the group of teachers who over 50 years old, the next is teachers between 41-50 years old, and the highest is 4.431 for teachers under 30 years old. Compared with other age groups, teachers over the age of 50 may not follow the teaching tasks in accordance with the teaching plan, on the contrary, they always choose teaching methods flexibly, and change the teaching plan flexibly accord to environmental variables.

TABLE 3-5

VARIANCE ANALYSIS OF PROFESSIONAL TEACHING KNOWLEDGE By AGE GROUPS

\begin{tabular}{|c|c|c|c|c|c|c|c|}
\hline Items & Ages & $\mathrm{N}$ & Mean & $\begin{array}{c}\text { St. } \\
\text { Deviation }\end{array}$ & $\begin{array}{c}\text { Between } \\
\text { Groups } \\
\text { Mean } \\
\text { Square } \\
\end{array}$ & $\mathrm{F}$ & Sig.(2-tailed) \\
\hline \multirow{4}{*}{$\mathrm{Z} 5$} & 30 and below & 44 & 3.4773 & 0.8209 & \multirow{4}{*}{9.879} & \multirow{4}{*}{20.118} & \multirow{4}{*}{$0.000 * *$} \\
\hline & $31-40$ & 71 & 3.6761 & 0.7126 & & & \\
\hline & $41-50$ & 39 & 4.1282 & 0.6561 & & & \\
\hline & Over 50 years old & 26 & 4.6923 & 0.4706 & & & \\
\hline \multirow{4}{*}{$\mathrm{Z7}$} & 30 and below & 44 & 4.3182 & 0.5612 & \multirow{4}{*}{0.776} & \multirow{4}{*}{1.671} & \multirow{4}{*}{0.175} \\
\hline & $31-40$ & 71 & 4.0282 & 0.6963 & & & \\
\hline & $41-50$ & 39 & 4.1026 & 0.7537 & & & \\
\hline & Over 50 years old & 26 & 4.1154 & 0.7114 & & & \\
\hline \multirow{4}{*}{$\mathrm{Z} 15$} & 30 and below & 44 & 4.1591 & 0.5682 & \multirow{4}{*}{0.361} & \multirow{4}{*}{0.800} & \multirow{4}{*}{0.496} \\
\hline & $31-40$ & 71 & 4.3099 & 0.6231 & & & \\
\hline & $41-50$ & 39 & 4.1282 & 0.8328 & & & \\
\hline & Over 50 years old & 26 & 4.1923 & 0.6939 & & & \\
\hline
\end{tabular}

TABLE 3-6

VARIANCE ANALYSIS OF FLEXIBLE TASK GOAL AWARENESS By AGE

\begin{tabular}{|c|c|c|c|c|c|c|c|}
\hline Items & Ages & $\mathrm{N}$ & Mean & St. Deviation & $\begin{array}{c}\text { Between } \\
\text { Groups } \\
\text { Mean } \\
\text { Square } \\
\end{array}$ & $\mathrm{F}$ & Sig.(2-tailed) \\
\hline \multirow{4}{*}{$\mathrm{Z} 16$} & 30 and below & 44 & 4.1136 & 0.7840 & \multirow{4}{*}{0.194} & \multirow{4}{*}{0.334} & \multirow{4}{*}{0.801} \\
\hline & $31-40$ & 71 & 3.9859 & 0.7268 & & & \\
\hline & $41-50$ & 39 & 4.0513 & 0.7236 & & & \\
\hline & $\begin{array}{c}\text { Over } 50 \text { years } \\
\text { old }\end{array}$ & 26 & 4.1154 & 0.8638 & & & \\
\hline \multirow{3}{*}{$\mathrm{Z} 17$} & 30 and below & 44 & 4.4773 & 0.5493 & \multirow{3}{*}{0.682} & \multirow{3}{*}{1.948} & \multirow{3}{*}{0.124} \\
\hline & $31-40$ & 71 & 4.2254 & 0.6368 & & & \\
\hline & $41-50$ & 39 & 4.2821 & 0.5595 & & & \\
\hline \multirow{5}{*}{$\mathrm{Z} 18$} & $\begin{array}{c}\text { Over } 50 \text { years } \\
\text { old }\end{array}$ & 26 & 4.4231 & 0.5777 & \multirow{5}{*}{3.127} & \multirow{5}{*}{6.810} & \multirow{5}{*}{$0.000 * *$} \\
\hline & 30 and below & 44 & 4.1591 & 0.7453 & & & \\
\hline & $31-40$ & 71 & 4.1831 & 0.6826 & & & \\
\hline & $41-50$ & 39 & 3.9231 & 0.6643 & & & \\
\hline & $\begin{array}{c}\text { Over } 50 \text { years } \\
\text { old }\end{array}$ & 26 & 4.6923 & 0.5491 & & & \\
\hline
\end{tabular}


TABLE 3-7

VARIANCE ANALYSIS OF OBJECTIVE CONSCIOUSNESS OF RIGID TASKS By AGE

\begin{tabular}{|c|c|c|c|c|c|c|c|}
\hline Items & Ages & $\mathrm{N}$ & Mean & St. Deviation & $\begin{array}{c}\text { Between } \\
\text { Groups } \\
\text { Mean } \\
\text { Square }\end{array}$ & $\mathrm{F}$ & Sig. \\
\hline \multirow{6}{*}{$\mathrm{Z3}$} & 30 and below & 44 & 4.6136 & 0.4925 & \multirow{6}{*}{0.310} & \multirow{6}{*}{1.334} & \multirow{6}{*}{0.265} \\
\hline & $31-40$ & 71 & 4.5634 & 0.4995 & & & \\
\hline & $41-50$ & 39 & 4.7436 & 0.4423 & & & \\
\hline & Over 50 years old & 26 & 4.6923 & 0.4706 & & & \\
\hline & 30 and below & 44 & 4.4318 & 0.5865 & & & \\
\hline & $31-40$ & 71 & 4.1831 & 0.7232 & & & \\
\hline \multirow[t]{3}{*}{$\mathrm{Z} 12$} & $41-50$ & 39 & 3.6667 & 0.8377 & \multirow[t]{2}{*}{14.874} & \multirow[t]{2}{*}{26.732} & \multirow[t]{2}{*}{$0.000 * *$} \\
\hline & Over 50 years old & 26 & 2.9231 & 0.8909 & & & \\
\hline & 30 and below & 44 & 4.1364 & 0.5536 & \multirow{4}{*}{0.403} & \multirow{4}{*}{0.893} & \multirow{4}{*}{0.446} \\
\hline \multirow[t]{3}{*}{$\mathrm{Z} 29$} & $31-40$ & 71 & 4.2394 & 0.6428 & & & \\
\hline & $41-50$ & 39 & 4.1538 & 0.8441 & & & \\
\hline & Over 50 years old & 26 & 4.3846 & 0.6373 & & & \\
\hline
\end{tabular}

\section{CONCLUSION}

A total of 180 minority English teachers of different ages in middle schools are involved as quantitative research participants in this study. SPSS is applied to analyze the status quo of their professional development attitude and the differences among teachers of different ages. The research findings as follows: minority English teachers in middle school have a strong positive attitude toward their professional development, and different ages have significant differences in the dimensions of Professional Teaching Knowledge, Flexible Task Goals Consciousness as well as Rigid Task Target Consciousness. The inadequacy of this study lies in the fact that due to the limited space, it is not able to present the detailed data of the quantitative research and in-depth interviews in detail. The follow-up research can focus on the impact of the professional development of ethnic minority foreign language teachers and the solutions to their confusion in teaching practice.

\section{REFERENCES}

[1] Aneja, G A. (2016). (Non)native speakered: Rethinking (Non)nativeness and teacher identity in TESOL teacher education. TESOL Quarterly, 3,572-569.

[2] Barkhuizen, G. (2016). A short story approach to analyzing teacher (imagined) identities over time. TESOL Quarterly, 3, 655-683.

[3] Borg, S. (1998). Teachers' pedagogical systems and grammar teaching: A qualitative study. TESOL Quarterly, 32(1), 9-38.

[4] Edwards, E., \& Burns, A. (2016). Language teacher-researcher identity negotiation: An ecological perspective. TESOL Quarterly, 3, 735-745.

[5] Ellis, E. M. (2016). "I may be a native speaker but I'm not monolingual": Reimagining all teachers' linguistic identities in TESOL. TESOL Quarterly, 3, 597-630.

[6] Ellis, R. (1997). SLA and language pedagogy. Studies in Second Language Acquisition, 20, 69-92.

[7] Freeman, D. (1989). Teacher training, development, and decision-making: A model of teaching and related strategies for teacher education. TESOL Quarterly, 23(1), 27-46.

[8] Freeman, D., \& Johnson, K. E. (1998). Re-conceptualising the knowledge base of language teacher education. TESOL Quarterly, 32, 397-417.

[9] Freeman, D., \& Richards, J. C. (1993). Conceptions of teaching and the education of second language teachers. TESOL Quarterly, 27(2), 193-216.

[10] Freeman, D., \& Richards, J. C. (Eds.). (1996). Teacher learning in language teaching. New York: Cambridge University Press.

[11] Johnson, K. E. (1996). The role of theory in L2 teacher education. TESOL Quarterly, 30, 765-772.

[12] Kasun, G. S., \& Saavedra, C. M. (2016). Disrupting ELL teacher candidates' identities: Indigenizing teacher education in one study abroad program. TESOL Quarterly, 3, 684-707.

[13] Lee, I. (2013). Becoming a writing teacher: Using "identity" as an analytic lens to understand EFL writing teachers' development. Journal of Second Language Writing, 3, 330-345.

[14] Lockhart, C., \& Richards, J. C. (1994). Reflective teaching in second language classrooms. New York: Cambridge University Press.

[15] Reeves, J. (2009). Teacher investment in learner identity. Teaching and Teacher Education, 25, 34-41.

[16] Richards, J. C. (1998). Beyond training. Cambridge: Cambridge University Press.

[17] Richards, J. C., \& Nunan, D. (1990). Second language teacher education. New York: Cambridge University Press.

[18] Velez-Rendon, G. (2010). From social identity to professional identity: Issues of language and gender. Foreign Language 
Annals, 43 (4), 635-649.

[19] Wallace, M. J. (1991). Training foreign language teachers: A reflective approach. Cambridge: Cambridge University Press.

[20] Woods, D. (1996). Teacher cognition in language teaching: Beliefs, decision-making and classroom practices. Cambridge: Cambridge University Press.

[21] Xunyang, (2012), Chinese English teacher's identity of senior high school- a case study of teachers of difference age in Shandong Province. Shanghai: doctoral dissertation, Shanghai Foreign Studies University.

[22] Ye Lan, Bai Yimin. (2001). New exploration of teacher roles and teacher development. Beijing: Educational Science Press.

[23] Yuan, R. (2016). Understanding higher education-based teacher educators' identities in Hong Kong: A sociocultural linguistics perspective. Asia-Pacific Journal of Teacher Education, 44 (4), 1-22.

[24] Zeichner, K., \& Liston, D. (1996). Reflective teaching: An introduction. Mahwah, NJ: Lawrence Erlbaum Associates.

[25] Zembylas, M. (2003). Emotions and teacher identity: A poststructural perspective. Teacher and Teaching: Theory and Practice, 9, 213-238.

[26] Zembylas, M. (2005). Discursive practice, genealogies, and emotional rules: A poststructuralist view on emotion and identity in teaching. Teaching and Teacher Education, 21, 935-948.

[27] Zhang Wentong, Kuang Chunwei. (2013). Basic course of SPSS statistical analysis. Beijing: Higher Education Press.

Hui Shi was born in Hunan Province, China in 1985. She received her doctoral degrees in foreign linguistics and applied linguistics from Southwest University, Chongqing, China. She is currently a lecturer in the Institute of International Education, Jishou University, Hunan, China. Her research field includes second language teacher education and applied linguistics. 